Revista da Sociedade Brasileira de Medicina Tropical

Journal of the Brazilian Society of Tropical Medicine

Vol.:52:e20190123: 2019

doi: 10.1590/0037-8682-0123-2019

\title{
Letter
}

\section{Are waste pickers at risk for hepatitis B and C infections because of poverty or environmental exposures?}

\author{
Cristiane Faria de Oliveira Scarponi[1], Tara Rava Zolnikov ${ }^{[2]}$ \\ and Marcos Paulo Gomes Mol ${ }^{[3]}$
}

\begin{abstract}
[1]. Diretoria do Instituto Octávio Magalhães. Fundação Ezequiel Dias, Belo Horizonte, MG, Brasil. [2]. Department of Community Health, National University, San Diego, CA, USA.

[3]. Diretoria de Pesquisa e Desenvolvimento, Fundação Ezequiel Dias, Belo Horizonte, MG, Brasil.
\end{abstract}

\section{Dear Editor:}

There are numerous direct and indirect adverse health effects related to socioeconomic disadvantage. Unfortunately, while many diseases persist simply because of the environment (e.g., poor housing, unimproved water, and sanitation, etc.), poor access to care is also a major contributing factor. This reduced healthcare accessibility can occur because of various reasons (e.g., cost, location, and physicians available), but it exists primarily owing to poverty. This situation contributes to an antagonistic scenario in which the people who are most exposed to illnesses are the most unlikely to receive care or treatment.

Two diseases that are wedged between the crux of poor environmental conditions and poverty are hepatitis B and C (HBV and HCV, respectively). These two infectious diseases are exacerbated by poverty; in fact, approximately $60 \%-70 \%$ of new cases occur annually and primarily affect the populations in low-income settings ${ }^{1,2}$. These infections are usually accompanied by poor outcomes because people are unable to access appropriate care (e.g., low resources, no money for treatment, etc. $)^{3}$. Unfortunately, work place environments are also associated with hepatitis B and C infections ${ }^{4}$. Unsanitary settings can be common among people who work and live in low socioeconomic conditions, and this scenario may directly and indirectly affect their health status ${ }^{2,5}$. Thus, both poverty and poor working conditions are factors that contribute to HBV and $\mathrm{HCV}$ infections.

Corresponding author: Dr. Marcos Paulo Gomes Mol.

e-mail: marcos.mol@funed.mg.gov.br

Orcid: 0000-0002-2568-3579

Received 21 March 2019

Accepted 30 May 2019
For waste pickers, both poverty and adverse environmental conditions are a reality. Waste picking is an important activity performed by people living in poverty; they sort through garbage to find recyclable material to exchange for money. There are many adverse health effects and high levels of morbidity associated with this individual-dependent occupation, ranging across physical, biological, and chemical hazards ${ }^{6}$. This situation contributes to a myriad of possible communicable disease exposures, including HBV that is often reported as a prevalent finding associated with needle sticks from improper or poor personal protective equipment use, incomplete or absent vaccination, and sorting through medical trash in an inadequate garbage collection system?

Waste picking is a common occupation throughout Brazil, which is home to more than 3,000 open air dumps? Throughout Brazil, hepatitis B susceptibility rates range from approximately $32 \%$ among individuals who live in poverty to $74.9 \%$ among Brazilian waste pickers ${ }^{8,9}$. According to Pereira ${ }^{10}$, the prevalence of HBV infection found among recyclable waste pickers was 2.4 times higher than that reported in a population-based study (5.3\%) in the same region. Modes of transmission typically occur through perinatal exposure, encountering infected blood or body fluid, or sexual intercourse. In the case of waste pickers, the primary route of exposure is likely through contact with contaminated biological and medical waste. Furthermore, most waste pickers do not wear personal protective equipment, which avails them to occupational exposures ${ }^{11}$. As such, Yusuf and colleagues ${ }^{12}$ suggested a HBV prevalence of $17.4 \%$ among waste pickers. This prevalence was reaffirmed by another recent study comparing a group of municipal waste collectors to a sample of white-collar employees not exposed to waste, in which a significantly higher prevalence of $\mathrm{HBV}$ infection was determined in waste collectors $(15 \%)$ than in white-collar employees $(2.5 \%$ anti-HBc positivity ${ }^{13}$. Klein and colleagues ${ }^{14}$ also found a high HBsAg (HBV) prevalence in Brazilian waste pickers at $12.3 \%$.

Additionally, hepatitis $\mathrm{C}$ is another disease that may be affecting waste pickers, with an increased association with 
poverty at an incidence rate of 3.58 ( $95 \%$ confidence interval $[\mathrm{CI}]=3.50,3.66)^{15}$. Greene and colleagues ${ }^{15}$ reported a population fraction of 0.45 that was attributable to chronic hepatitis C, suggesting that $45 \%$ of chronic hepatitis $\mathrm{C}$ cases might not have occurred if people were not exposed to extreme cases of poverty and its associated effects. In waste pickers, a high index (47.3\%) of accidents with sharps and needles was reported among recyclable garbage handlers by Marinho and colleagues ${ }^{9}$, confirming blood exposure. However, HCV infection was not more frequent in the recyclable garbage handlers than in the general population, and sexually transmitted disease history was a predictor of infection ${ }^{9}$. According to a recent literature review about $\mathrm{HBV}$ and $\mathrm{HCV}$ in this population, environmental determinants and social vulnerability suggested an increased risk to workers exposed to wastes compared with those not exposed $\mathrm{d}^{4}$. Although not as thoroughly investigated in waste pickers, $\mathrm{HCV}$ is another disease that could equally affect this population because of poverty and poor working conditions (e.g., increased exposure to biological contaminants).

Thus, $\mathrm{HBV}$ and $\mathrm{HCV}$ in waste pickers is a multidimensional topic that highlights the encompassing issues of poverty and poor working conditions. That said, this situation could be improved by reviewing the environment to pinpoint factors that may be targeted for change. Is it the worksite conditions or general poverty contributing to increased rates of hepatitis B and C? Some scientific discussions have suggested that the rates of hepatitis B and C could increase because of poverty, while other studies confirmed that exposures occur because of medical waste and biological contaminants. This type of information could emphasize areas of improvement to decrease both hepatitis B and $\mathrm{C}$ infections in an at-risk population. Moreover, epidemiological studies should be conducted to clarify contributing factors influencing the risks of hepatitis $\mathrm{B}$ or $\mathrm{C}$ infection in the waste pickers population. Hepatitis B vaccinations are currently recommended in Brazil for all populations, including a focus on marginalized populations like waste pickers. Although an $\mathrm{HCV}$ vaccination is currently unavailable, a program focusing on waste pickers in general would likely benefit this population.

\section{Conflict of Interest}

The authors declare that there is no conflict of interest.

\section{Financial Support}

This research received no specific grant from any funding agency in the public, commercial, or not-for-profit sectors.

\section{REFERENCES}

1. Nayagam S, Thursz M, Sicuri E, Conteh L, Wiktor S, Low-Beer D, et al. Requirements for global elimination of hepatitis B: a modelling study. Lancet Infect Dis. 2016;16(12):1399-408.
2. World Health Organization (WHO). Global report for research on infectious diseases of poverty. Technical Report Series. Geneva: WHO; 2012. 168p.

3. Chappuis M, Pauti MD, Tomasino A, Fahet G, Cayla F, Corty JF. Knowledge of HIV and hepatitis B and C status among people living inextreme poverty in France, in 2012. Med Mal Infect. 2015;45: $72-7$.

4. Mol M, Greco D, Cairncross S, Heller L. Hepatitis B and C in household and health services solid waste workers. Cad Saude Publica. 2015;31(sup):S295-S300.

5. Heller L, Cairncross S. Poverty. In: Bartram J, with Baum R, Coclanis PA, Gute DM, Kay D, McFadyen S, Pond K, Robertson W, Rouse MJ editor. Routledge Handbook of Water and Health. New York: Routledge; 2015. p. 376-86.

6. Rachiotis G, Papagiannis D, Markas D, Thanasias E, Dounias G, Hadjichristodoulou C. Hepatitis B virus infection and waste collection: prevalence, risk factors and infection pathway. Am J Ind Med. 2012;55(7):650-5.

7. Zolnikov TR, Costa de Silva R, Tuesta AA, Marques CP, Cruvinel VRN. Ineffective waste site closures in Brazil: A systematic review on continuing health conditions and occupational hazards of waste collectors. Waste Manag. 2018;80:26-39. doi: 10.1016/j. wasman.2018.08.047.

8. Belhassen-García M, Pérez Del Villar L, Pardo-Lledias J, Gutiérrez Zufiaurre MN, Velasco-Tirado V, Cordero-Sánchez M, et al. Imported transmissible diseases in minors coming to Spain from low-income areas. Clin Microbiol Infect. 2015;21(4):370.e5-8.

9. Marinho TA, Lopes CLR, Teles SA, Matos ME, Matos MAD, Kozlowski AG, et al. Epidemiology of hepatitis B virus infection among recyclable waste collectors in central Brazil. Rev Soc Bras Med Trop. 2014;47(1):18-23.

10. Pereira LMMB, Martelli CMT, Moreira RC, Merchan-Hamman E, Stein AT, Cardoso MRA, et al. Prevalence and risk factors of Hepatitis C virus infection in Brazil, 2005 through 2009: a crosssectional study. BMC Infect. Dis. 2013:13:60.

11. Ravindra K, Kaur K, Mor S. Occupational exposure to the municipal solid waste workers in Chandigarh, India. Waste Man Res. 2016;34(11):1192-5.

12. Yusuf RO, Sawyerr HO, Adeolu AT, Habeeb LM, Abolayo TT. Seroprevalence of Hepatitis B Virus and Compliance to Standard Safety Precautions among Scavengers in Ilorin Metropolis, Kwara State, Nigeria. J Health Pollut. 2018;8(19):180914.

13. Tsovili E, Rachiotis G, Symvoulakis EK, Thanasias E, Giannisopoulou O, Papagiannis D, et al. Municipal waste collectors and hepatitis $\mathrm{B}$ and $\mathrm{C}$ virus infection: a cross-sectional study. Infez Med. 2014;22(4):271-6.

14. Klein G, Botelho TKR, Cordova CMM, Livramento A. High prevalence of HBV carriers among waste collectors in the largest landfill in Latin America. Revista De Patologia Tropical / Journal of Tropical Pathology. 2018;47(1):5-10.

15. Greene SK, Levin-Rector A, Hadler JL, Fine AD. Disparities in Reportable Communicable Disease Incidence by Census TractLevel Poverty, New York City, 2006-2013. Am J Public Health. 2015;105(9):e27-34. 